\title{
Prospects for Bilingual Education Curriculum in Turkey: A Mainstream Issue
}

\author{
Burhan Ozfidan ${ }^{1} \&$ Hasan Aydin ${ }^{2}$ \\ ${ }^{1}$ College of Education, Texas A\&M University, College Station, TX, United States \\ ${ }^{2}$ College of Education, Florida Gulf Coast University, Fort Myers, FL, United States \\ Correspondence: Burhan Ozfidan, College of Education, Texas A\&M University, College Station, TX, United \\ States. E-mail: b.ozfidan@tamu.edu
}

Received: August 25, 2017

Accepted: September 20, 2017

Online Published: September 25, 2017

doi: $10.5539 /$ hes.v7n4p25

URL: http://doi.org/10.5539/hes.v7n4p25

\begin{abstract}
The goal of bilingual education is fostering academic achievement, assisting immigrant acculturation to a new community, enabling native speakers to learn a second language, conserving linguistic and cultural heritage of minority groups, and advancing national language resources. This study investigated how certain parameters such as the views and attitudes towards bilingual education and curriculum development may affect the development of a bilingual education curriculum in Turkey. This study is significant because it could pave the way for developing a bilingual education program in Turkey. This study used an explanatory sequential mixed method, conducted in two phases: a quantitative phase followed by a qualitative phase. For quantitative data collection, 140 participants responded the survey instrument. For qualitative data collection, 4 participants were interviewed. The results indicated that a bilingual education curriculum is necessary for the education system in Turkey because the population of minority peoples is quite large. Results also reflected that a bilingual education program in Turkey should focus on speaking, listening, writing, reading, and on the development of vocabulary. Universities should open language teacher training departments for teachers who are going to teach in two languages. Examining and implementing elements of bilingual education models from other countries could prove helpful in establishing an efficient bilingual education program in Turkey.
\end{abstract}

Keywords: bilingual education, curriculum, mixed method

\section{Introduction}

Bilingual education is defined as an educational system in which information is presented to students in two languages (Baker, 2011). The goal of bilingual education, according to Ngai (2002), is fostering academic achievement, assisting immigrant acculturation to a new community, enabling native speakers to learn a second language, conserving linguistic and cultural heritage of minority groups, and advancing national language resources. Ngai (2002) also states that bilingual education in school includes teaching children in their native language and teaching all topics in two different languages. Bilingual education has also been shown to help a student's self-esteem and promote biculturalism, and the students need to recognize and comprehend the importance of their language and culture (Baker, 2000). Students should not have to feel badly or different regarding their origins, the language they speak, or the traditions they have. Bilingualism also supports the ability of students to learn another culture in addition to their own (Hakuta, 1990).

Bilingual education reform has affirmative consequences for the educational and linguistic achievement of students. Children benefit from learning how to use deep language understanding effectively as they pursue their schooling from their elementary, secondary, and high school periods, and they can improve their capabilities in two different languages (Cummins, 2008). Children can identify the differences and similarities between two languages they speak, and, once they develop literacy in both languages, they gain practice in processing information. Bilingual education expert, Jim Cummins, has stated that more than 150 research studies in last 35 years meaningfully support the idea that "the person who knows only one language does not truly know that language" (Cummins, 2001, p. 3). Because of processing information through two distinct languages, Cummins (2001) believes that children who are bilingual may also improve their mental flexibility and cognition. 
For potential educational reform in Turkey, policy in education should recognize the minority groups who have poor Turkish language backgrounds once they start their schooling (Kadizade, 2015; Ozfidan \& Ugurlu, 2015). The most realistic way to eliminate discrimination between majority and minority students when they begin school is to use their mother tongue in education within a bilingual education model (Kaya, 2015). Being taught in the mother tongue was considered a human right and educational reform by UNESCO in 1974. For a potential educational reform, needs, conditions, and accessible objectives should be recognized and the current questions, detailed observations regarding education system, and different circumstances should be considered to cultivate a strong model for the education system in Turkey (Aydin \& Ozfidan, 2014; Icduygu, 2015).

Teacher training departments should be established as a first step in bilingual educational reform. Teacher training is one of the most essential concerns for a bilingual education program (Lasagabaster, 2001; Rodriguez, 1998). For the necessary infrastructure of teacher training, colleges of education in Turkey should open relevant departments such as a Department of Teacher Education (Kyriakou \& Kaya, 2011) for bilingual education program training programs. Teachers in training should be focused on cultural diversity and linguistics (Rodriguez, 1998) for bilingual educational reform in Turkey (Faltis, 2014). Within the teacher-training program, pedagogical courses should be required for guidance on teaching children whose mother tongue is different from others (Cummins, 2000). Trainees who teach mostly students who have different ethnic background should also be provided in-service training on cultural diversity and linguistics.

Understanding the differences between learning and education is essential. Learning is the capacity of an individual's brain to obtain and retain information for a lifetime, whereas education provides assistance in further strengthening a student's learning ability with a curriculum and resources including teachers, classroom environment, libraries, etc. (Ozfidan, Machtmes, \& Demir, 2014). Every student is fundamentally equal when he or she enters the schools or educational environments; however, students who don't speak Turkish have a disadvantage in the Turkish educational system as all primary and secondary school instruction is given in Turkish (Kaya, 2015).

This study investigated how certain parameters such as the views and attitudes towards bilingual education and curriculum development may affect the development of a bilingual education curriculum in Turkey. This study is significant because it could pave the way for developing a bilingual education program in Turkey.

\section{Method}

This study utilized an explanatory sequential mixed method, conducted in two phases: a quantitative phase followed by a qualitative phase. The explanatory sequential mixed method began with the gathering and analyzing quantitative data. In the second phase, qualitative data were collected and analyzed as a follow-up to the quantitative results.

\subsection{Data Settings and Analysis}

For quantitative data, descriptive analysis was used describe the basic features of the data and to provide simple summaries about the sample and the measures in the study. Data that was interval in nature was reported in means and standard deviations.

This study utilized semi-structured interviewing for several reasons. First, this type of interview is frequently used when a researcher wants to understand all facets of the answers provided and to inquire intensely into a topic, which is, for the purposes of this study, bilingual education. Second, by using a semi-structured interview, this study collected detailed information in a style that was conversational. Third, a semi-structured interview was utilized so that questions could be answered in a certain order. Without deviation from the script, the interview closely approximated the survey being read aloud. The researcher anticipated similar answers to those given in the survey and analyzed the detailed answers as sources of information and knowledge needed to answer the specific questions.

The interviews were conducted using a digital recording in the native language of the participants, which enabled the researcher to organize and collect data precisely. Additionally, notes were taken during; these interviews were elaborated upon and clarified post-interview. While analyzing the data, comprehensive notes and unedited transcripts were used as reference tools.

Although integrating and combining quantitative and qualitative phases can improve and increase the understanding of the research findings, some pros and cons exist for using a mixed method (Hanson, Creswell, Plano-Clark, Petska, \& Creswell, 2005). To eliminate all the potential reported disadvantages of mixed method approach such as conflicting data and theory, the study utilized only the strengths of both the quantitative and qualitative approaches thus using a mixed method that provided a more holistic picture of the research. 


\subsection{Participants}

For quantitative data collection, 140 participants responded the survey instrument. Participants included 96 males and 44 females. For qualitative data collection, 4 participants were interviewed; 2 of whom were Turkish and the other 2 had ethnic backgrounds other than Turkish. In accordance with the IRB guidelines of Texas A\&M University (reference \#043138) (Appendix A), the participations were voluntary, and they could drop out at any phase of the study if they did not want to continue. Table 1 shows the areas of Turkey, which the respondents identified as home region.

Table 1. Regions of participants in Turkey

\begin{tabular}{llcccc}
\hline$\#$ & Region & \% of total & N & Male & Female \\
\hline 1 & Marmara Region & 24.29 & 34 & 25 & 9 \\
2 & Aegean Region & 10.71 & 15 & 7 & 8 \\
3 & Mediterranean Region & 10.00 & 14 & 8 & 6 \\
4 & Central Anatolia Region & 18.57 & 26 & 21 & 5 \\
5 & Black Sea Region & 10.71 & 15 & 10 & 5 \\
6 & Eastern Anatolia Region & 15.00 & 21 & 14 & 7 \\
7 & Southeastern Anatolia Region & 10.71 & 15 & 11 & 4 \\
& Total & $100 \%$ & 140 & 96 & 44 \\
\hline
\end{tabular}

Table 1 indicates the geographic spread of the participants across Turkey. There are seven regions in Turkey, and participants represented each region in this study. Most participants were from the Marmara Region because this region has the highest population in Turkey. Some those who participated in study were living in the United States; however, they all grew up in Turkey, and they selected the region from whence they came.

Turkey is a mosaic with a diversity of cultures. Table 2 below indicates that many people from different ethnic backgrounds participated in the study. This table also shows that the study has participants who are culturally and linguistically diverse. Most who participated were Turks, and the minority were Circassians. All the participants knew Turkish; some also knew the language of their specific ethnic group.

Table 2. Ethnic and linguistic background of participants

\begin{tabular}{llllllll}
\hline & \multicolumn{2}{c}{ Ethnic Background } & \multicolumn{5}{c}{ Linguistic Background } \\
\hline$\#$ & Ethnicity & \% of total & N & $\#$ & Language & \% of total & N \\
\hline 1 & Turkish & 58.57 & 82 & 1 & Turkish & 61.43 & 86 \\
2 & Kurdish & 20.71 & 29 & 2 & Kurdish & 14.29 & 20 \\
4 & The Laz & 12.86 & 18 & 3 & The Zaza & 11.43 & 16 \\
5 & The Alevi & 2.86 & 4 & 4 & Arabic & 7.14 & 10 \\
6 & Circassian & 0.71 & 1 & 5 & The Laz & 5.71 & 8 \\
7 & The Zaza & 2.86 & 4 & & & & \\
8 & Arab & 7.14 & 10 & & & & \\
\hline
\end{tabular}

\subsection{Reliability and Validity}

For reliability, Cronbach's alpha was used to analyze the questionnaire data. Because factor analysis was used, Cronbach's alpha scores were created while running the data on SPSS. Cronbach's alpha internal consistency measure was found to be high across all 11 items $(\alpha=.98)$. For Cronbach's alpha, a minimum value of .70 is considered acceptable (Nunnally, 1978). Hence, the survey instrument was reliable.

Likewise, academicians who are experts in the field of bilingual education in Turkey and the United States reviewed the questionnaires for content/face validity. The results for validity in the survey indicated a statistically 
significant correlation. The correlation $(\mathrm{rs}=.520, \mathrm{p}=.000)$ can be considered to be a moderate/medium correlation (.40-.60) (See Laerd Statistics, n.d.). Therefore, this questionnaire was found to have content validity.

\section{Findings}

\subsection{Results of Quantitative Data Analysis}

Table 3 below provides an overall summary of the descriptive findings about curriculum-related issues. This table emphasizes that a curriculum should be designed for a bilingual education model in Turkey (Item 1). Respondents believed that an education program in Turkey should focus on speaking, listening, writing, reading, and on the development of vocabulary (Items 2, 3, 4, 5, and 6). Universities should open language teacher training departments for teachers who are going to teach in two languages (Item 7). This table also highlights that teachers should demonstrate their proficiency in both languages before they can teach in bilingual classrooms, and materials used in schools should be available in both languages (Items 8 and 9). Lastly, models of bilingual education programs from different countries should be considered as samples for developing a bilingual education model in Turkey (Items 10 and 11).

Table 3. Items and percentage of participants about curriculum related issues

\begin{tabular}{|c|c|c|c|c|c|c|}
\hline$\#$ & Statement & Strongly Disagree & Disagree & Neutral & Agree & Strongly Agree \\
\hline 1 & $\begin{array}{l}\text { A curriculum should be designed for a bilingual } \\
\text { education model in Turkey. }\end{array}$ & $\begin{array}{c}5.00 \% \\
(7)\end{array}$ & $\begin{array}{c}5.71 \% \\
(8)\end{array}$ & $\begin{array}{c}3.57 \% \\
(5)\end{array}$ & $\begin{array}{c}49.29 \% \\
(69)\end{array}$ & $\begin{array}{c}36.43 \% \\
(51)\end{array}$ \\
\hline 2 & $\begin{array}{l}\text { Bilingual education programs should focus on } \\
\text { speaking. }\end{array}$ & $\begin{array}{c}3.60 \% \\
(5)\end{array}$ & $\begin{array}{l}7.91 \% \\
(11)\end{array}$ & $\begin{array}{c}4.32 \% \\
(6)\end{array}$ & $\begin{array}{c}53.24 \% \\
(74)\end{array}$ & $\begin{array}{c}30.94 \% \\
(43)\end{array}$ \\
\hline 3 & $\begin{array}{l}\text { Bilingual education programs should focus on } \\
\text { listening. }\end{array}$ & $\begin{array}{c}5.80 \% \\
(8)\end{array}$ & $\begin{array}{c}6.52 \% \\
(9)\end{array}$ & $\begin{array}{c}5.80 \% \\
(8)\end{array}$ & $\begin{array}{c}29.71 \% \\
(41)\end{array}$ & $\begin{array}{c}52.17 \% \\
(72)\end{array}$ \\
\hline 4 & $\begin{array}{l}\text { Bilingual education programs should focus on } \\
\text { writing. }\end{array}$ & $\begin{array}{l}5.04 \% \\
(7)\end{array}$ & $\begin{array}{c}9.35 \% \\
(13)\end{array}$ & $\begin{array}{c}3.60 \% \\
(5)\end{array}$ & $\begin{array}{c}33.09 \% \\
(46)\end{array}$ & $\begin{array}{c}48.92 \% \\
(68)\end{array}$ \\
\hline 5 & $\begin{array}{l}\text { Bilingual education programs should focus on } \\
\text { reading. }\end{array}$ & $\begin{array}{c}4.35 \% \\
(6)\end{array}$ & $\begin{array}{c}8.70 \% \\
(12)\end{array}$ & $\begin{array}{l}2.17 \% \\
(3)\end{array}$ & $\begin{array}{c}38.41 \% \\
(53)\end{array}$ & $\begin{array}{c}46.38 \% \\
(64)\end{array}$ \\
\hline 6 & $\begin{array}{l}\text { Bilingual education programs should focus on } \\
\text { the development of vocabulary. }\end{array}$ & $\begin{array}{c}5.80 \% \\
(8)\end{array}$ & $\begin{array}{l}7.97 \% \\
(11)\end{array}$ & $\begin{array}{l}6.52 \% \\
(9)\end{array}$ & $\begin{array}{c}44.20 \% \\
(61)\end{array}$ & $\begin{array}{c}35.51 \% \\
(49)\end{array}$ \\
\hline 7 & $\begin{array}{l}\text { Universities should open language teacher } \\
\text { training departments for teachers who are going } \\
\text { to teach in two languages. }\end{array}$ & $\begin{array}{c}5.71 \% \\
(8)\end{array}$ & $\begin{array}{c}6.43 \% \\
(9)\end{array}$ & $\begin{array}{l}3.57 \% \\
(5)\end{array}$ & $\begin{array}{c}43.57 \% \\
(61)\end{array}$ & $\begin{array}{c}40.71 \% \\
(57)\end{array}$ \\
\hline 8 & $\begin{array}{l}\text { Teachers should demonstrate their proficiency in } \\
\text { both languages before they are allowed to teach } \\
\text { in bilingual classrooms. }\end{array}$ & $\begin{array}{l}5.00 \% \\
(7)\end{array}$ & $\begin{array}{c}6.43 \% \\
(9)\end{array}$ & $\begin{array}{l}5.71 \% \\
(8)\end{array}$ & $\begin{array}{c}40.71 \% \\
(57)\end{array}$ & $\begin{array}{c}42.14 \% \\
(59)\end{array}$ \\
\hline 9 & $\begin{array}{l}\text { Materials used in schools should be available in } \\
\text { both languages. }\end{array}$ & $\begin{array}{c}4.29 \% \\
(6)\end{array}$ & $\begin{array}{c}6.43 \% \\
(9)\end{array}$ & $\begin{array}{l}5.00 \% \\
(7)\end{array}$ & $\begin{array}{c}33.57 \% \\
(47)\end{array}$ & $\begin{array}{c}50.71 \% \\
(71)\end{array}$ \\
\hline 10 & $\begin{array}{l}\text { The government should finance the preparation } \\
\text { of school materials. }\end{array}$ & $\begin{array}{l}2.88 \% \\
(4)\end{array}$ & $\begin{array}{l}5.04 \% \\
(7)\end{array}$ & $\begin{array}{l}2.16 \% \\
(3)\end{array}$ & $\begin{array}{c}29.50 \% \\
(41)\end{array}$ & $\begin{array}{c}60.43 \% \\
(84)\end{array}$ \\
\hline 11 & $\begin{array}{l}\text { Different countries bilingual education models } \\
\text { should be considered as a bilingual education } \\
\text { model in Turkey. }\end{array}$ & $\begin{array}{c}4.32 \% \\
(6)\end{array}$ & $\begin{array}{c}8.63 \% \\
(12)\end{array}$ & $\begin{array}{l}3.60 \% \\
(5)\end{array}$ & $\begin{array}{c}23.74 \% \\
(33)\end{array}$ & $\begin{array}{c}59.71 \% \\
(83)\end{array}$ \\
\hline
\end{tabular}

Notes. Items 3, 5, and 6 had 138 respondents; Items 2, 4, 10, and 11 had 139 respondents. The remainder had 140 respondents. $1=$ Strongly Disagree, $2=$ Disagree, $3=$ Neutral, $4=$ Agree, and 5=Strongly Agree.

Table 4 shows the mean scores and standard deviation values of each item in Table 3 . The highest mean score in this table was 4.26 , which was for the statement "the government should finance the preparation of school materials". This indicates that respondents believed that the government should financially support the preparation of school materials. The lowest mean score was 3.96, which was "bilingual education programs should focus on 
the development of vocabulary". This finding suggests that respondents believed that bilingual education programs should focus on the development of vocabulary. Table 4 also shows that the $3^{\text {rd }}$ and $4^{\text {th }}$ items, which were "bilingual education programs should focus on listening" and "bilingual education should focus on writing" had the highest standard deviations at 1.16, which indicates that a high level of differentiation existed for this item. The $10^{\text {th }}$ item, which was "the government should finance the preparation of school materials", had the lowest standard deviation value at .97 that emphases a low level of differentiation. According to Bland and Altman (1996), "a high standard deviation indicates a heterogeneous group" (p. 48).

Table 4. Perception scale on curriculum related issues (Mean scores and standard deviation values)

\begin{tabular}{|c|c|c|c|}
\hline \# & Items & Mean & SD \\
\hline 1 & A curriculum should be designed for a bilingual education model in Turkey. & 4.06 & 1.04 \\
\hline 2 & Bilingual education programs should focus on speaking. & 4.00 & 1.00 \\
\hline 3 & Bilingual education programs should focus on listening. & 4.16 & 1.16 \\
\hline 4 & Bilingual education programs should focus on writing. & 4.12 & 1.16 \\
\hline 5 & Bilingual education programs should focus on reading. & 4.14 & 1.10 \\
\hline 6 & Bilingual education programs should focus on the development of vocabulary. & 3.96 & 1.13 \\
\hline 7 & $\begin{array}{l}\text { Universities should open language teacher training departments for teachers who are } \\
\text { going to teach in two languages. }\end{array}$ & 4.07 & 1.10 \\
\hline 8 & $\begin{array}{l}\text { Teachers should demonstrate their proficiency in both languages before they are } \\
\text { allowed to teach in bilingual classrooms. }\end{array}$ & 4.09 & 1.09 \\
\hline 9 & Materials used in schools should be available in both languages. & 4.20 & 1.08 \\
\hline 10 & The government should finance the preparation of school materials. & 4.40 & 0.97 \\
\hline 11 & $\begin{array}{l}\text { Different countries bilingual education models should be considered as a bilingual } \\
\text { education model in Turkey. }\end{array}$ & 4.26 & 1.14 \\
\hline
\end{tabular}

Notes. Items 3, 5, and 6 had 138 respondents; Items 2, 4, 10, and 11 had 139 respondents. The remainder had 140 respondents.

\subsection{Results of Qualitative Data Analysis}

Overall, the study found that respondents believed a bilingual education program might have highly affirmative influences on minority groups in Turkey. The common idea that was found from the perspective of the interviewees was that a bilingual education program in Turkey might preserve the linguistic knowledge and cultural heritage of minority groups and help to integrate individuals or groups into mainstream society. Such a program might also increase understanding of languages and cultural variety, and create strong relationships between different ethnic groups.

The study also found that a bilingual education program, according to the common opinions of all the interviewees, might provide affirmative action with respect to the academic achievements and integration of minority groups into society at large. Interviewees felt that a bilingual education would provide language skills that help in gaining employment and increasing the educational success of students. They also felt that bilingual education would promote peace among different ethnic groups in Turkish society.

Elements of the bilingual education models of different countries should be considered for inclusion into a bilingual education program to be developed in Turkey. For example, the situation of the minority languages in Turkey can be compared with those of Spain and Canada (Ozfidan, 2014). To provide an efficient education system, the differing needs of various regions should be considered. Basically, this can be realized in examples of Canada's consideration of the French language and Spain's consideration of the Basque language (Ozfidan, Burlbaw, \& Kuo, 2016). Most interviewees whose origins were Turkish and non-Turkish (ethnically different than Turkish) asserted that a bilingual educational model should be improved for the education of minority students. Crucial lessons should be drawn from the implementation of educational measures such as those being currently employed by Spain and Canada's bilingual education programs.

An interviewee who is an expert in the field of bilingual education and who had a different ethnical background than Turkish stated that drawing lessons from the bilingual education programs of other countries might prevent 
the Turkish government from encountering the obstacles that other countries faced. He also said "adapting a model in Turkey like the Basque models would allow students to recognize and display a more positive attitude towards school. Implementing a bilingual model would also help students' self-confidence and therefore affect their school achievement". He continued that bilingual education programs in Spain and Canada would be a great fit for our country. Models from these two countries should be examined, and the types of difficulties that they faced should be noted as they were working on their bilingual education programs.

Another interviewee who is an expert in the field of English Language Learning and who was of Turkish ethnical origin stated that examining and implementing elements of bilingual education models from other countries could prove helpful in establishing an efficient bilingual education program in Turkey. He also continued that:

Students who acquire an effective and enhanced education will be able to improve communication with other cultures and languages and will feed on the intercultural dialogue essential for societal peace. We can see such an effective bilingual education program in Basque bilingual education in Spain. Implementation of Basque bilingual education models should positively be taken into consideration during the development of policies in Turkey regarding the use of the mother tongue as a bilingual education.

He stated that experts in the field of language learning, particularly in bilingual education should be allowed to examine the pros and cons of a bilingual education program in Turkey. He also said that:

Monitoring Basque Country's efficient bilingual models should provide inspirations for the development of a potential bilingual education model in Turkey. The problems inherent in Basque bilingual models should be studied while establishing policies for education in the mother language in Turkey.

Educational models should be developed for the mother tongue education and be revised continuously according to the students' needs. However, some of the interviewees highlighted that implementing other countries' bilingual education program might be problematic since every country has a different education system; therefore, their needs might be different then our country.

All in all, these experts in the field of language learning indicated their feelings about how drawing lessons from different countries bilingual education could help in developing a bilingual education program in Turkey. The common idea of these two experts was that the challenges and issues from the bilingual education program of different countries should be detected so that Turkey could avoid some potential issues and difficulties (Krashen, 2000).

Thus, respondents believed that a bilingual education program could help preserve ethnic and religious identity and socialize people to participate in the community at large in Turkey. As a common idea, all interviewees indicated that language is critical factor for academic achievement. Most minority children whose Turkish is not good usually do not continue their education in Turkey, and most children lose fluency in their mother tongue because they do not have an opportunity to use their languages. Children who do not speak their mother tongue might also not be able to communicate with their parents at home. Bilingual education is an opportunity to gain equal access to education on the part of students having a different mother tongue than most other students. This type of education also enables minority students to be more comfortable psychologically. Lastly, all interviewees stated that a bilingual education program in Turkey might solve the conflict between different ethnic groups and bring happiness to the society. According to the general notion of all interviewees, a bilingual education program in Turkey would preserve the linguistic and cultural heritage of minority groups and help build stronger relationships among different ethnic groups. It also would help provide equality of opportunity for students and acceptance of cultural diversity. Interviewees also stated that a bilingual education program would help to resolve social conflicts among ethnic groups and psychologically benefit students from different ethnic minorities.

\section{Discussion and Conclusion}

The results reflected that a bilingual education curriculum was necessary for the education system in Turkey because the population of minority peoples is quite large (approximately 30\%). Respondents also believed that a bilingual education program in Turkey should focus on speaking, listening, writing, reading, and on the development of vocabulary. Universities should open language teacher training departments for teachers who are going to teach in two languages. Teachers who are going to teach in two languages should demonstrate their proficiency in both languages before they can teach in bilingual classrooms, and materials used in schools should be available in both languages. Respondents believed that bilingual education programs developed in other countries should be examined for possible use in Turkey. In doing so, the challenges that other countries faced 
could be examined, and, therefore, a Turkish bilingual program could develop solutions to potential stumbling blocks beforehand. In this way, Turkey might avoid time-taking false starts and errors and move forward more quickly. Perhaps bilingual educational systems like the Basque program in Spain and French immersion program in Canada could provide useful elements upon which Turkey could draw.

According to findings, the bilingual education models of different countries should be taken into consideration in developing a bilingual education program in Turkey. These included measures being currently employed by Spanish and Canadian bilingual education programs. All participants in the interviews mentioned that adopting elements of bilingual education programs from other countries might prevent the Turkish government from encountering would-be problems by examining what other countries had done. Challenges and issues in present in the bilingual education programs of other countries should be studied, and the lessons learned should be incorporated into a Turkish system (Ilhan \& Aydin, 2015).

According to both quantitative and qualitative data analysis, the structure of bilingual education models of other countries should be considered in developing a bilingual education program in Turkey. Lessons learned from the development and implementations of these models could help Turkey to avoid the problematic issues that other bilingual countries have faced. This study mentioned the cases of Spain and France, which are two countries having bilingual education programs. The study discussed the challenges and benefits of these bilingual education programs and compared them with the potential development of a bilingual education program in Turkey. The experts in the field of bilingual education should also examine the pros and cons of establishing a bilingual education program in Turkey.

\section{References}

Aydin, H., \& Ozfidan, B. (2014). Perceptions on mother tongue based multicultural and bilingual education in Turkey. Multicultural Education Review (MER), 6(1), 51-78.

Baker, C. (2000). A parents' and teachers' guide to bilingualism (2nd ed.). Clevedon, England: Multilingual Matters.

Baker, C. (2011). Foundations of bilingual education and bilingualism (5th ed.). New York: Multilingual matters.

Bland, J. M., \& Altman, D. G. (1996). Statistics notes: Measurement error. The BMJ, 313, 744. https://doi.org/10.1136/bmj.313.7059.744

Cummins, J. (2000). Language, power and pedagogy: Bilingual children in the crossfire. Clevedon, UK: Multilingual Matters.

Cummins, J. (2001). Bilingual children's mother tongue: Why is it important for education? Sprogforum, 7(19), $15-20$.

Cummins, J. (2008). Teaching for transfer: Challenging the two solitudes assumption in bilingual education. In J. Cummins, \& N. H. Hornberger (Eds.), Encyclopedia of Language and Education 5 (2nd ed., pp. 1528-1538). New York: Springer. https://doi.org/10.1007/978-0-387-30424-3_116

Faltis, C. (2014). Toward a Race Radical Vision of Bilingual Education for Kurdish Users in Turkey: A Commentary. Journal of Ethnic and Cultural Studies, 1(1), 1-5.

Hakuta, K. (1990). Language and cognition in bilingual children. Bilingual education: Issues and strategies, 47-59.

Hanson, W. B., Creswell, J. W., Plano-Clark, Y. L., Petska, K. S., \& Creswell, D. (2005). Mixed methods research designs in counseling psychology. Journal of Counseling Psychology, 52(2), 224-235. https://doi.org/10.1037/0022-0167.52.2.224

Icduygu, A. (2015). Syrian refugees in Turkey: The long road ahead. Washington, DC: Transatlantic Council of Migration, a Project of the Migration Policy Institute. Retrieved from https://www.scribd.com/document/263865431/Syrian-Refugees-in-Turkey-The-Long-Road-Ahead

Ilhan, D., \& Aydin, H. (2015). Perceptions of Higher Education Faculty Members on Bilingual Education in Turkey. Journal of Education and Training Studies, 3(3), 146-163. https://doi.org/10.11114/jets.v3i3.694

Kadizade, E. D. (2015). Identifying accurate equivalents between Turkish and Arabic for foreign language teaching. Educational Research and Reviews, 10(4), 501. https://doi.org/10.5897/ERR2014.2024

Kaya, N. (2015). Teaching in and studying minority languages in Turkey: A brief overview of current issues and minority schools. European Yearbook of Minority Issues Online, 12(1), 315-338. https://doi.org/10.1163/9789004306134_013 
Kaya, Y. (2015). The Opinions of Primary School, Turkish Language and Social Science Teachers regarding Education in the Mother Tongue (Kurdish). Journal of Ethnic and Cultural Studies, 2(2), 33-46.

Krashen, S. (2000). Bilingual education: Current challenges. Educators for Urban Minorities, 1(2), 53-68.

Kyriakou, N., \& Kaya, N. (2011). Minority rights: Solutions to the Cyprus conflict. London: Minority Rights Group International.

Laerd Statistics. (n.d.). Pearson product moment correlation. Retrieved from https://statistics.laerd.com/statistical-guides/pearson-correlation-coefficient-statistical-guide.php

Lasagabaster, D. (2001). Bilingualism, immersion programmes and language learning in the Basque country. Journal of Multilingual and Multicultural Development, 22(5), 401-425. https://doi.org/10.1080/01434630108666443

Ngai, P. B. (2002). Bilingual education for all: A benefits model for small towns. Bilingual Research Journal, 26(2), 269-294. https://doi.org/10.1080/15235882.2002.10668711

Nunnally, J. C. (1978). Psychometric theory (2nd ed.). New York: McGraw-Hill.

Ozfidan, B. (2014). The Basque bilingual education system: A model for a Kurdish bilingual education system in Turkey. Journal of Language Teaching and Research, 5(2), 382-390. https://doi.org/10.4304/jltr.5.2.382-390

Ozfidan, B., \& Ugurlu, O. (2015). The Idea of Race and Racial Differences. Electronic International Journal of Education, Arts, and Science, 1(1), 85-98.

Ozfidan, B., Burlbaw, L., \& Kuo, L. J. (2016). Perceptions of an Anticipated Bilingual Education Program in Turkey. International Education Studies, 9(10), 174. https://doi.org/10.5539/ies.v9n10p174

Ozfidan, B., Machtmes, K., \& Demir, H. (2014). Socio-cultural Factors in Second Language Learning: A Case Study of Adventurous Adult Language Learners. European Journal of Education Research, 3(4), 185-191. https://doi.org/10.12973/eu-jer.3.4.185

Rodriguez, R. F. (1998). Project BESTT: Bilingual/ESL special education teacher training. Silver City, NM: Western New Mexico University, School of Education. Retrieved from http://files.eric.ed.gov/fulltext/ED462819.pdf

UNESCO. (1974). Recommendation concerning education for international understanding, co-operation and peace and education relating to human rights and fundamental freedoms. Adapted by the General Conference at its Eighteenth Session, Paris, 17 October-23 November. Retrieved from http://unesdoc.unesco.org/images/0011/001140/114040e.pdf\#page=144 


\section{Appendix}

\section{IRB OUTCOME LETTER}

DIVISION OF RESEARCH

RTM TEXAS A\&M

DATE: September 21, 2016

\section{MEMORANDUM}

TO: Lynn M Burlbaw

TAMU - College Of Education \& Human Dev - Teaching, Learning And Culture

FROM: Dr. David Martin

SUBJECT: Expedited Approval - Reference $\# 043138$

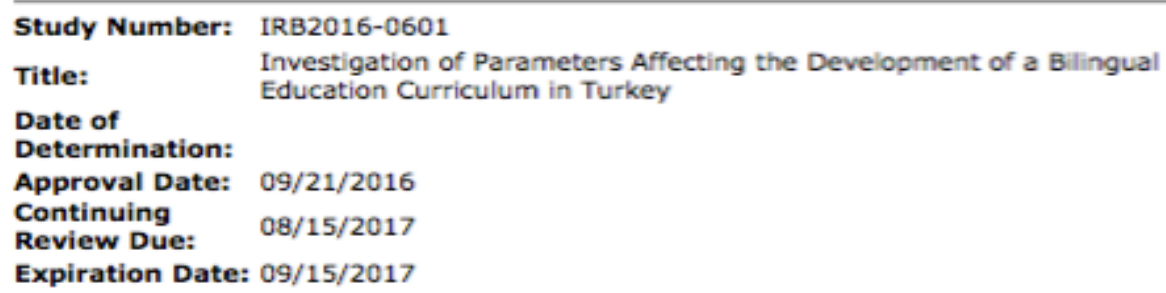

Only IRB-stamped approved versions of study materials (e.g., consent forms, recruitment materials, and questionnaires) can be distributed to human participants. Please log into iRIS to download the stamped, Documents hoproved version of all study materials. If you are unable to locate the Reviewed and approved version of all study materials. If you are unable to locate Approved: $\quad 979.845 .4969$ or the IRB liaison assigned to your area.

\begin{tabular}{|c|c|c|c|}
\hline \multicolumn{4}{|c|}{ Submission Components } \\
\hline \multicolumn{4}{|c|}{ Study Document } \\
\hline Title & Version Number & Version Date & Outcome \\
\hline $\begin{array}{l}\text { Survey } \\
\text { Questions }\end{array}$ & Version 1.1 & $08 / 17 / 2016$ & Approved \\
\hline $\begin{array}{l}\text { Interview } \\
\text { Questions }\end{array}$ & Version 1.1 & $08 / 17 / 2016$ & Approved \\
\hline \multicolumn{4}{|c|}{ Study Consent Form } \\
\hline Title & Version Number & Version Date & Outcome \\
\hline $\begin{array}{l}\text { consent form } \\
\text { for interview }\end{array}$ & Version 1.2 & $08 / 17 / 2016$ & Approved \\
\hline $\begin{array}{l}\text { consent form } \\
\text { for survey } \\
\text { instrument }\end{array}$ & Version 1.3 & $08 / 17 / 2016$ & Approved \\
\hline
\end{tabular}

Document of Consent: Written consent in accordance with 45 CF $46.116 / 21$ CFR 50.27 Waiver approved under 45 CFR 46.117 (c) 1 or 2/ 21 CFR 56.109 (c) 1 Waiver of Consent:

750 Agronomy Road, Suite 2701 1186 TAMU

College Station, TX 77843-1186

Tel. 979.458.1467 Fax. 979.862.3176

http://rcb.tamu.edu 
- This study has been approved for 200 participants.

- This IRB study application has been reviewed and approved by the IRB. Research may begin on the approval date stated above.

Comments:

- Research is to be conducted according to the study application approved by the IRB prior to implementation.

- Any future correspondence should include the IRB study number and the study title.

\section{Investigators assume the following responsibilities:}

1. Continuing Review: The study must be renewed by the expiration date in order to continue with the research. A Continuing Review application along with recuired documents must be submitted by the continuing review deadline. Failure to do so may result in processing delays, study expiration, and/or loss of funding.

2. Completion Report: Upon completion of the research study (including data collection and analysis), a Completion Report must be submitted to the IRB.

3. Unanticipated Problems and Adverse Events: Unanticipated problems and actverse events must be reported to the IRB immediately.

4. Reports of Potential Non-compliance: Potential non-compliance, including deviations from protoco and violations, must be reported to the IRB office immediately.

5. Amendments: Changes to the protocol and/or study documents must be requested by submitting an Amendment to the IRB for review. The Amendment must be approved by the IRB before being implemented.

6. Consent Forms: When using a consent form or information sheet, the tRB stamped approved version must be used. Please log into iRIS to download the stamped approved version of the consenting instruments. If you are unable to locate the stamped version in iRIS, please contact the iRIS Support Team at 979.845 .4969 or the IRB liaison assigned to your area. Human participants are to receive a copy of the consent document, if appropriate.

7. Post Approval Monitoring: Expedited and full board studies may be subject to post approval monitoring. During the life of the study, please review and document study progress using the PI self-assessment found on the RCB website as a method of preparation for the potential review. Investigators are responsible for maintaining complete and accurate study recorts and making them available for post approval monitoring. Investigators are encouraged to request a pre-initiation site visit with the Post Approval Monitor. These visits are designed to help ensure that all necessary documents are approved and in order prior to initiating the study and to help investigators maintain compliance.

8. Recruitment: All approved recruitment materials will be stamped electronically by the hepp staff and available for download from iRIS. These IRB-stamped approved documents from iRIS must be used for recruitment. For materials that are distributed to potential participants electronically and for which you can cnly feasibly use the approved text rather than the stamped document, the study's IRB Study Number, approval date, and expiration dates must be included in the following format: TAMU IRB: $20 X X$ -

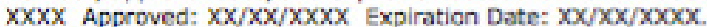

9. FERPA and PPRA: Investigators conducting research with students must have appropriate approvals from the FERPA administrator at the institution where the research will be conducted in accordance with the Family Education Rights and Privacy Act (FERPA). The Protection of Pupil Rights Amendment (PPRA) protects the rights of parents in students ensuring that written parental consent is required for participation in surveys, analysis, or evaluation that ask questions falling into categories of protected information.

10. Food: Any use of food in the conduct of human research must follow Texas Ass University Standard Administrative Procedure 24.01.01.M4.02

11. Payments: Any use of payments to human research participants must follow Texas ASM University Standard Administrative Procedure 21.01.99,M0.03.

12. Records Retention: Federal Regulations recuire records be retained for at least 3 years. Records of a study that collects protected health information are required to be retained for at least 6 years. Some sponsors require extended records retention. Texas A3M University nule 15.99.03.M1.03 Responsible Stewardship of Research Data requires that research records be retained on Texas ASM property.

\section{Copyrights}

Copyright for this article is retained by the author(s), with first publication rights granted to the journal.

This is an open-access article distributed under the terms and conditions of the Creative Commons Attribution license (http://creativecommons.org/licenses/by/4.0/). 